\title{
In vitro evaluation of three different biomaterials as scaffolds for canine mesenchymal stem cells ${ }^{1}$
}

\author{
Oduvaldo Câmara Marques Pereira-Junior', Sheila Canevese Rahal ${ }^{I I}$, João Ferreira Lima-Neto ${ }^{\text {III }}$, Fernanda da Cruz Landim- \\ Alvarenga $^{\mathrm{IV}}$, Frederico Ozanan Barros Monteirov \\ IFellow PhD degree, Postgraduate Program in Veterinary Medicine, Department of Veterinary Surgery and Anesthesiology, School of Veterinary \\ Medicine and Animal Science, UNESP, Botucatu-SP. Intellectual and scientific content of the study, technical procedures, manuscript writing. \\ IIPhD, Full Professor, Department of Veterinary Surgery and Anesthesiology, School of Veterinary Medicine and Animal Science, UNESP, Botucatu- \\ SP. Conception and design of the study, manuscript writing, critical revision (Researcher level 1B CNPq). \\ IIIFellow PhD degree, Postdoctoral scholar, Department of Animal Reproduction and Veterinary Radiology, School of Veterinary Medicine and Animal, \\ UNESP, Botucatu-SP. Acquisition of data, technical procedures. \\ ${ }^{\text {IV }} \mathrm{PhD}$, Full Professor, Department of Animal Reproduction and Veterinary Radiology, School of Veterinary Medicine and Animal, UNESP, Botucatu- \\ SP. Conception and design of the study, manuscript writing, critical revision (Researcher level 1D CNPq). \\ ${ }^{\text {Iv }} \mathrm{PhD}$, Associate Professor, Federal Rural University of the Amazon, Institute of Animal Health and Production, Belem do Para-PA. Critical revision.
}

\footnotetext{
ABSTRACT

PURPOSE: To evaluate in vitro ability the of three different biomaterials - purified hydroxyapatite, demineralized bone matrix and castor oil-based polyurethane - as biocompatible 3D scaffolds for canine bone marrow mesenchymal stem cell (MSC) intending bone tissue engineering.
}

METHODS: MSCs were isolated from canine bone marrow, characterized and cultivated for seven days with the biomaterials. Cell proliferation and adhesion to the biomaterial surface were evaluated by scanning electron microscopy while differentiation into osteogenic lineage was evaluated by Alizarin Red staining and Sp7/Osterix surface antibody marker.

RESULTS: The biomaterials allowed cellular growth, attachment and proliferation. Osteogenic differentiation occurred in the presence of hydroxyapatite, and matrix deposition commenced in the presence of the castor oil-based polyurethane.

CONCLUSION: All the tested biomaterials may be used as mesenchymal stem cell scaffolds in cell-based orthopedic reconstructive therapy.

Key words: Hydroxyapatites. Bone Matrix. Castor Oil. Polyurethanes. Stem Cells. 


\section{Introduction}

Stem cells are defined by their ability for self-renewal and survival while maintaining genomic integrity ${ }^{1-3}$. The bone marrow has at least three stem cell populations - hematopoietic stem cells, endothelial progenitor cells and also mesenchymal stem cells (MSCs) - which are precursors of non hematopoietic tissues ${ }^{1-4}$. The MSCs are able to differentiate themselves into other phenotypes including those that produce cartilage, muscle tissue, bone, medullar stroma, tendon/ligament, and other connective tissues when exposed to an appropriate stimulus ${ }^{1,5-7}$. In vitro, the MSCs may be grown directly or after density gradient separation; however, cell density is a critical factor affecting the cell growth ${ }^{8}$. Morphologically, the MSCs are mostly fusiform and cuboidal ${ }^{7,9}$.

A standard protocol to isolate bone marrow MSCs is based on their expansion potential and on the adherence of marrow-derived fibroblast-like cells, and lack of adherence of marrow-derived hematopoietic cells, to the plastic substrate of the cell culture plate ${ }^{8-11}$. In addition, MSCs possess immunophenotype characteristics as well as specific cell-surface markers, and are negative for hematopoietic markers such as CD3, CD14, CD19, CD34, CD38 and CD66 but positive for CD105, CD166, CD54, CD 55, CD13 and CD446,7,911,12. The characterization is generally accomplished on culture-expanded cells and not on primary cells ${ }^{8}$.

Since the repair of large bone defects still poses a challenge for the orthopaedic, reconstructive and maxillo-facial surgeon $^{13}$, several approaches have been used to treat them ${ }^{13}$ ${ }^{17}$. Although the autogenous cancellous bone graft is the most effective treatment for inducing bone regeneration and repair since it provides viable osteogenic cells ${ }^{18,19}$, it has disadvantages such as the requirement for a second surgical site, insufficient sites, and morbidity at the donor site ${ }^{16,19,20}$. Thus, bone-graft substitutes including hydroxyapatite, tricalcium phosphate, coral-collagen composite, natural coral, calcium carbonate-based ceramics and collagen combinations have been developed to treat a number of orthopedic diseases ${ }^{19-22}$. In addition, some of these materials allow direct anchorage to the local tissue. Due to this characteristic, these biomaterials have been used as scaffolds in reconstructive surgeries with excellent results while avoiding the use of bone grafts $^{23}$. However, it is recognized that some biomaterials lack either osteogenic or osteoinductive properties ${ }^{19,24}$

According to tissue engineering concepts it is possible to regenerate several tissues or organs by using mature cells or stem cells seeded onto adequate three-dimensional scaffolds ${ }^{9,19,24}$. Vats et $a l .{ }^{25}$ described the steps involved in the engineering of tissues and organs. These include cell harvest from the donor site, seeding of cells onto a scaffold, stimulation of cellular proliferation, maintaining or stimulating cellular specialization or differentiation and, finally, transplant of the living tissue or organ to the patient. The final goal is the creation of a stable, complex three-dimensional construction of clinically useful size in vivo, combining all these steps.

An ideal scaffold for bone tissue engineering must provide an appropriate environment for tissue development; it should favor cell attachment, growth and differentiation and have biocompatible components ${ }^{19,26}$. Scaffolds may be derived from biological materials such as extracelullar matrix, plants and algae; or synthetic materials including hydroxyapatite, tricalcium phosphate ceramics, polylactide and polyglycolide, or a combination of these $\mathrm{e}^{9,27}$. However, the scaffolds that deliver MSCs should have the following characteristics: be mechanically sensitive to the implantation site, be able to osteointegrate into the host tissues or disappear, be porous, allow cell attachment, growth and differentiation, permit bioactive molecules to have access to cells, provide maximal bone growth through osteoinduction and/or osteoconduction, and be sterilizable without loss of properties ${ }^{5,19}$. The differentiation capacity of cultured bone marrow-derived MSCs coupled with the apparent ease of ex vivo culture manipulation has engendered considerable interest in potential therapeutic applications of these cells in a wide range of settings ${ }^{28}$. Furthermore, the anti-proliferative and anti-inflammatory effects shown by these cells have also provided a basis for their application to disease therapies ${ }^{7}$. Therefore, the association of these biomaterials and cells with osteogenic potential may be a viable and promising alternative in the treatment of bone defects as observed in animal models ${ }^{2,9,19,24}$. Thus, the aim of this study was to investigate three different types of commercially available biomaterials as biocompatible 3D scaffolds for canine MSCs, intending bone tissue engineering.

\section{Methods}

The present study was performed according to the guidelines for the care and use of laboratory animals and was approved by the Ethics Committee from the School of Veterinary Medicine and Animal Science, UNESP at Botucatu.

\section{Scaffolds}

BioOsteo $^{\circledR}$ (Biomecânica Indústria e Comércio de Produtos Ortopédicos Ltda., Brazil) in granule presentation ( $800 \mu \mathrm{m}$ in diameter) with pores of 1 to $2 \mu \mathrm{m}$, is a polyurethane 
containing castor oil (soft segment), associated with calcium carbonate $(34.5 \%$ concentrated/concentration). The $500 \mathrm{mg}$ sample of polyurethane used in each culture flask is ethylene oxide sterilized.

Bonefill $^{\circledR}$ (Bionnovation Produtos Biomédicos SA, Brazil.) is a granular biomaterial (0.6-1.5 $\mathrm{mm}$ in diameter) composed of inorganic matrix obtained from bovine bone and ethylene oxide sterilized. A $500 \mathrm{mg}$ sample was used in each culture flask.

Hydroxyapatite $^{\circledR}$ (Bionnovation Produtos Biomédicos $\mathrm{SA}$, Brazil) (granules of approximately $0.6 \mathrm{~mm}$ in diameter) is a ceramic mineral (hydroxyapatite) produced by precipitation of calcium phosphate and ethylene oxide sterilized. A $500 \mathrm{mg}$ sample was used in each culture flask.

\section{Cell Isolation}

Canine MSCs were isolated and expanded using a modification of methods previously reported ${ }^{29}$. Bone marrow aspirate was obtained from an adult healthy dog humerus under general anesthesia. A bone marrow biopsy needle was inserted through the cortical bone of the humeral major tuberculum and $5 \mathrm{ml}$ of bone marrow was aspirated into a syringe containing $1 \mathrm{ml}$ of sodium heparin. The aspirate was centrifuged at $1.500 \mathrm{rpm}$ for $10 \mathrm{~min}$ to remove serum and fat. The cell-rich sediment was then diluted at the proportion of 1/1 with Dulbecco's Modified Eagle Medium (DMEM) high glucose with L-glutamin (GIBCO BRL; Grand Island, USA). Four ml was transferred to a tube containing $4 \mathrm{ml}$ of Ficoll-Paque $(1.077 \mathrm{~g} / \mathrm{ml})$ for density gradient centrifugation at $300 \mathrm{~g}$ for $40 \mathrm{~min}$. Immediately afterwards, the mononuclear cell ring was collected and washed with DMEM twice. The cells were then diluted in $1 \mathrm{ml}$ DMEM with $20 \%$ fetal calf serum (FCS), transferred to culture flasks of $25 \mathrm{~cm}^{2}$ with $5 \mathrm{ml}$ of DMEM (low glucose with L-glutamine), FCS, penicillin and streptomycin and cultured in a humidified 5\% $\mathrm{CO}_{2}$ atmosphere at $37.5^{\circ} \mathrm{C}$. MSCs were selected on the basis of adhesion and proliferation on tissue culture plastic substrate. Once the cells achieved $80 \%$ confluence at seven days of culture, they were resuspended to a concentration of $2 \times 10^{7}$ cells $/ \mathrm{ml}$. To confirm the mesenchymal stem cell lineage, CD34 and CD44 specific surface antibodies (AbD Serotec, Oxford, UK) were used to mark the mesenchymal cells. The cell populations isolated on first passage culture were prepared according to the antibodies manufacturer protocols. The CD34 antibody FITC (Fluorescein Isothiocyanate) conjugated was negative at direct immunofluorescence staining for flow cytometry. The CD44 antibody associated with RPE secondary antibody (R. Phycoerythrin) was positive at indirect immunofluorescence staining for flow cytometry. In the following experiments the MSCs were used prior to passage 2.

\section{Cell seeding and morphology}

The scaffolds were placed in a $75 \mathrm{~cm}^{2}$ cell culture flask at the previously described concentration. MSCs were seeded onto the scaffolds at a density of $2 \times 10^{6}$ cells/flask and the medium containing DMEM (low glucose with L-glutamine), 20\% FCS, penicillin, streptomycin and amphotericin B was added until reaching $15 \mathrm{ml}$. The cells and scaffolds were maintained at $37.5^{\circ} \mathrm{C}$ in a humidified 5\% $\mathrm{CO}_{2}$ atmosphere for seven days. To observe the cell morphology, phase contrast microscopy was used at days 2, 4 and 7 of cell culture.

\section{Cell differentiation and adhesion}

At day seven, the scaffolds were removed from the cell culture flasks by gently washing with complete culture medium then soaked in a buffered $2.5 \%$ glutaraldehyde solution for scanning electron microscopy (SEM). The adherent cells in the culture flask were washed twice with phosphate-buffered saline (PBS) to completely remove the biomaterials granules and then stained with Alizarin Red solution to detect calcium deposits. Furthermore, adherent cells were also re-suspended and marked with Sp7/Osterix surface marker antibody for osteogenic differentiation.

SEM was used to evaluate the cell attachment and growth. The biomaterial samples associated with the mesenchymal stem cells were assessed in a Quanta 200 3D Scanning Electron Microscope (Fei Company, Hillsboro, USA). The samples were prepared according to the usual protocol. In addition, isolated samples of all biomaterials were evaluated by SEM.

\section{Results}

\section{In vitro evaluation of cell response with biomaterial}

After two days of cell culture, cell growth in monolayer was verified in all areas of the culture flask, independently of the BioOsteo granule concentration in the area. The cells reached 60$70 \%$ confluence and showed morphological preservation despite the vacuoles of different sizes found inside their cytoplasm. After being cultured for four days, the cells reached $70-80 \%$ confluence and the morphology was maintained. On day seven, several 
granules of the BioOsteo had adhered to the surface of the culture flask and there were cells in contact with the granules. The cells reached approximately $80-90 \%$ confluence in all areas of the culture flask, and around the BioOsteo granules (Figure 1a).

On the second day of cell culture, intense cell proliferation was verified throughout the culture flask containing Bonefill samples. The cells had fibroblastoid morphology with $60-70 \%$ confluence. After being cultured for four days, the cells reached $90 \%$ confluence in all areas of the culture flask and maintained fibroblastoid morphology. On day seven, the cells showed about $90 \%$ confluence and some of them had commenced growing toward the surfaces of the Bonefill granules (Figure 1b).

On day two of cell culture, the cells with hydroxyapatite showed slower cell proliferation than BioOsteo and Bonefill. The cells showed a fibroblastoid phenotype, with a confluence ranging from 40 to $60 \%$. After being cultured for four and seven days, the cells reached $80 \%$ confluence (Figure 1c), and the granules of the hydroxyapatite showed fragmentation giving rise to small fragments throughout the culture flask.

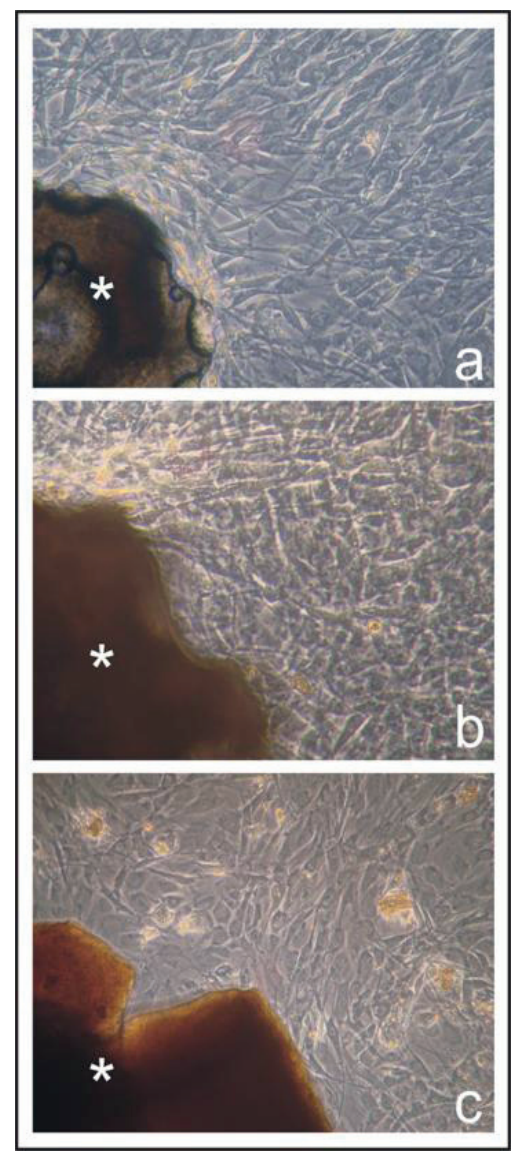

FIGURE 1 - Phase microscopy at seven days of cell culture. Cell morphology and spreading in the presence of the BioOsteo (a), Bonefill (b), and Hidroxyapatite (c) granules $\left(^{*}\right)$. Observe the high cellular confluence with the three biomaterials.

\section{Cell differentiation markers}

After seven days of culture, Alizarin Red staining revealed no calcium deposition in the cell monolayer for the BioOsteo and Bonefill (Figures 2a and 2b). However, the hydroxyapatite showed little deposition of extracellular calcium in the hydroxyapatite (Figure 2c). Anti-Sp7/Osterix antibody was positive only in relation to cells cultivated in the presence of hydroxyapatite granules (Figure 2d).

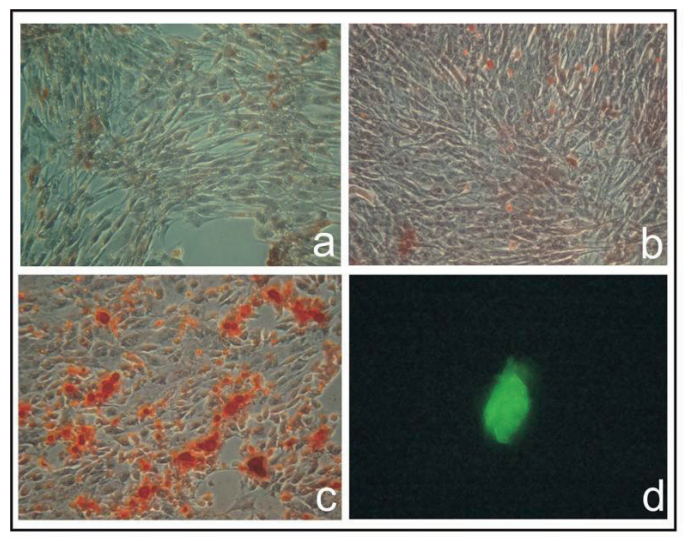

FIGURE 2 - Comparison at seven days of cell culture of the Alizarin red solution staining among the cells cultured in the presence of BioOsteo (a), Bonefill (b), and Hidroxyapatite (c) granules. Observe calcium deposition stained only when the hidroxyapatite was added to the cell culture. Observe the osteogenic differentiation of one cell cultured with hidroxyapatite granules confirmed by the anti-Sp7/Osterix cell surface antibody (d).

\section{SEM}

The isolated samples of BioOsteo showed irregular granules with no pores, diameters ranging from 300 to $800 \mu \mathrm{m}$ (Figure 3a), and surface areas varying from smooth to rough (Figure 3b). The evaluation of BioOsteo combined with the MSCs revealed cells with fibroblastoid morphology aggregated at the surface of all granules (Figure 3c). Furthermore, approximately $90 \%$ of the granules had spherical hydroxyapatite-like structures adhering to their surface, surrounding the cells (Figure 3d). 


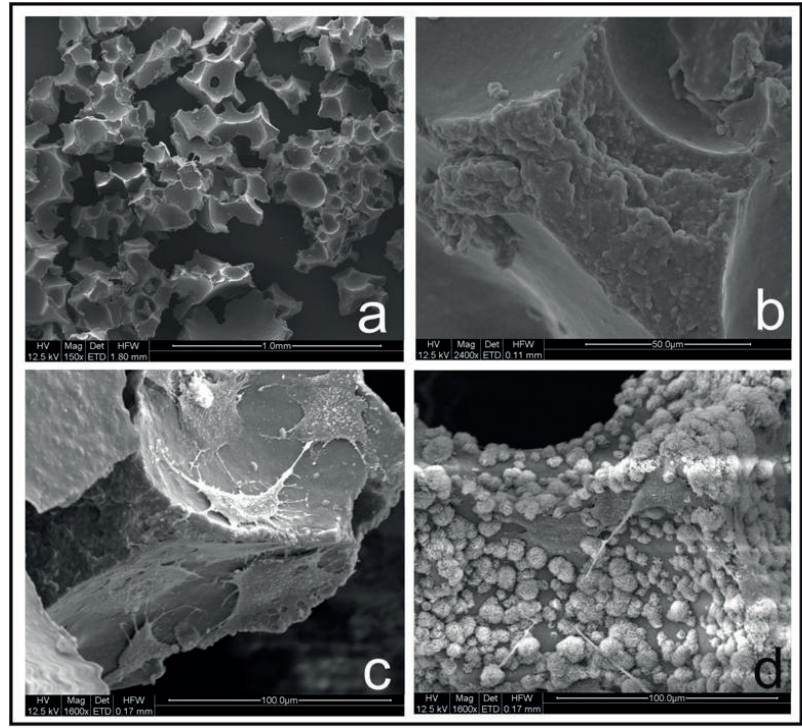

FIGURE 3 - Ultrastructure of the BioOsteo granules under scanning electron microscopy. Observe irregular granules (a), with both smooth and rough surface (b). After cultured for seven days with MSC, observe cells attached to the biomaterial surface (c) and calcified matrix deposition around the cells $(\mathbf{d})$.

The Bonefill samples without the MSCs showed irregular granules with diameters between 1000 and $2000 \mu$ m (Figure 4a). The granules presented rough irregular surfaces and showed few pores on its surface (Figure 4b). The MSC-Bonefill combination showed marked cell aggregation covering almost the entire granular surface (Figure 4c). The cells had fibroblastoid morphology with several cytoplasmatic extensions directed toward both adjacent cells and the biomaterial's surface (Figure 4d).

SEM of the isolated hydroxyapatite sample revealed irregular granules ranging from 500 to $1000 \mu \mathrm{m}$ in diameter (Figure $5 a)$. The granules presented irregular topography, rough surfaces and pores up to $5 \mu \mathrm{m}$ in diameter (Figure $5 \mathrm{~b}$ ). The evaluation of Hydroxyapatite combined with the MSCs showed few cells aggregated on the granular surface (Figure 5c). Although the cells had fibroblastoid morphology, their diameters (approximately $50 \mu \mathrm{m}$ ) were smaller (Figure 5d) than those observed in the

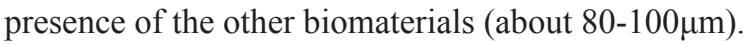

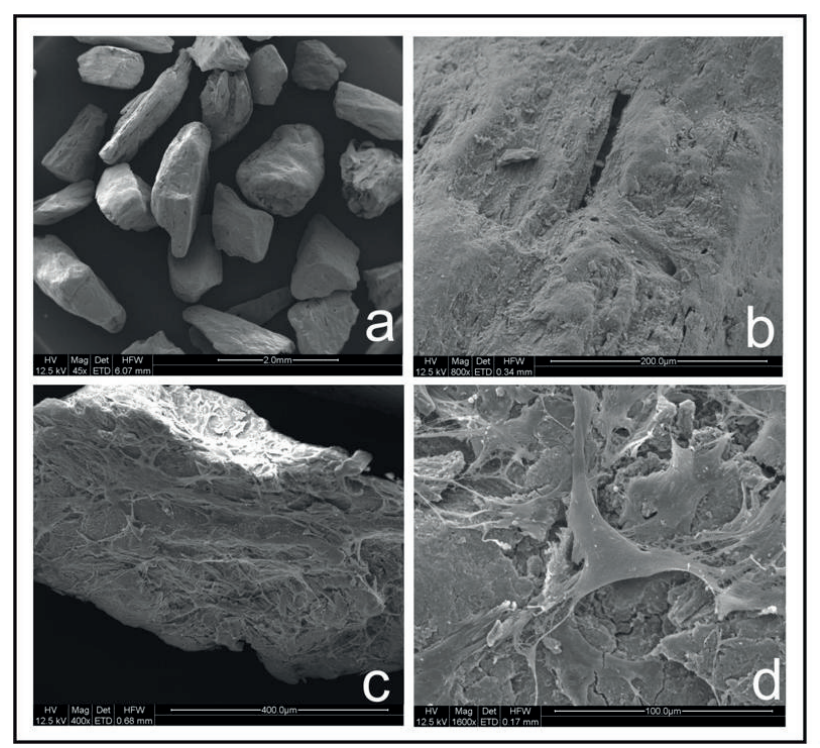

FIGURE 4 - Scanning electron microscopy of Bonefill granules. Observe irregular granules (a), and Havers and Volkmann channels at the biomaterial surface (b). After cultured for seven days with MSC, observe marked cell aggregation covering almost the entire granular surface (c) and fibroblastoid morphology of the attached cells (d).

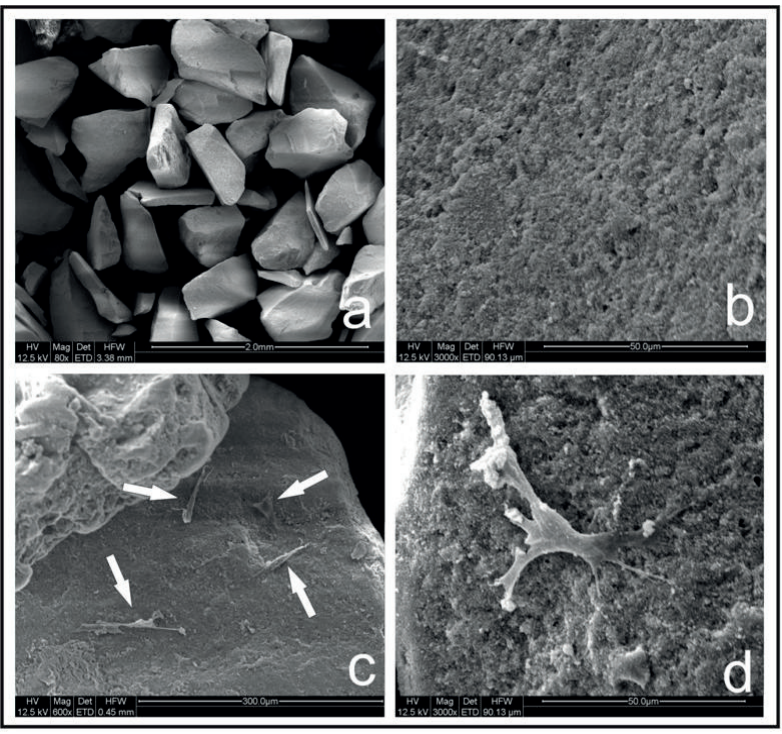

FIGURE 5 - Scanning electron microscopy of the hidroxyapatite granules showing irregular granules (a) with rough surfaces and pores up to $5 \mu \mathrm{m}$ in diameter (b). After cultured for seven days with MSC, observe few cells (arrows) aggregated on the granular surface (c) with fibroblastoid morphology and small diameter (approximately $50 \mu \mathrm{m})(\mathbf{d})$.

\section{Discussion}

We investigated three different scaffolding biomaterials for canine MSCs. Castor oil-based polyurethane (soft segment) is developed from two basic components (polyol and pre-polymer), both obtained by modification of the castor oil plant ${ }^{30}$. Calcium 
carbonate is added to the polyurethane in order to improve its capacity to integrate with the osseous tissue ${ }^{31}$. Many commercial presentations of BioOsteo are available, allowing multiple uses, while the granule presentation used in this study is indicated as bone filler ${ }^{17,30}$. In the presence of this polyurethane, the MSCs maintained the fibroblastoid phenotype, which is the typical MSC morphology ${ }^{9}$ throughout the evaluation time. Under phase microscopy, the MSCs showed proliferation sufficient to achieve widespread distribution in all culture flasks, even near the biomaterial granules. At day seven of cell culture, many granules were attached to the culture flask surface and surrounded by cells. The calcium carbonate of the polyurethane formulation may be responsible for this attachment, since it enhances the osseous integration of the polyurethane ${ }^{31}$. Furthermore, the surrounding cells should also support the adhesion of the granules. It was reported that the chemical composition of the castor oil-based polyurethane did not affect the rat bone marrow-cell adhesion to its surface, but the cell proliferation and mineralized nodule formation under osteoinductive medium was prominent when the calcium carbonate or, better yet, calcium phosphate was added to the polyurethane composition ${ }^{32}$.

The BioOsteo presented irregular granules whose surfaces varied from smooth to rough, as revealed by SEM. Although the exact biomaterial surface characteristics that allow great adhesion to cells are not completely elucidated, the roughness and topography of this surface influence the cell adhesion and proliferation ${ }^{19}$. In the present study, the MSCs adhered preferentially to the smooth surfaces of the BioOsteo. In addition, almost $90 \%$ of the BioOsteo granules cultured with the MSCs showed spherical hydroxyapatite-like structures. According to the manufacturer, after the polymerization, the final product shows a quantity of urethane chains that attract the organic calcium compounds in the process of bone integration ${ }^{30}$, which may favor the crystal deposition by the adhering cells. Although the Alizarin Red staining and Osterix/Sp7 marking were negative, the intense deposition of hydroxyapatite-like crystals by the adhering cells suggests the commencement of osteogenic differentiation and the osteoinductive property of BioOsteo. On the other hand, no pores were detected on the granular surface, which is considered undesirable. The biomaterial permeability enables the influx of nutrients and the removal of metabolic waste ${ }^{19}$. Furthermore, the minimal pore size that facilitates cell penetration is $20 \mu \mathrm{m}$, and the pores must be larger than $50 \mu \mathrm{m}$ to allow new bone formation within them ${ }^{33}$.

Demineralized bone matrix produced by acid extraction of allograft cortical bone contains osteoinductive factors such as bone morphogenetic protein, growth factors and TGF-- $B$; and noncollagenous proteins that are considered osteoconductive ${ }^{34,35}$. In the present study these characteristics may have contributed to the faster cell proliferation in the presence of the Bonefill granules, which allowed $90 \%$ confluence at day four. This was also confirmed by SEM after seven days in culture, when almost all granules were covered by adhering MSCs. Similar results were reported when human MSCs were seeded over three resorbable biomaterials (calcium-deficient hydroxyapatite, $\beta$-tricalcium phosphate and demineralized bone matrix) of which demineralized bone matrix produced the best cell adhesion ${ }^{36}$. The demineralized bone matrix is presented in several forms such as granules, powder, gel, putty and strips, in which the potency of the preparations depends on the manufacturing process ${ }^{20,35}$. The one used in this study was granular, obtained from bovine cortical bone, with a rough irregular surface, and no pores except the Havers and Volkmann channels. The phase microscopy at day seven of cell culture with the Bonefill granules showed the maintenance of the fibroblastoid phenotype, as observed in the other tested biomaterials. Although the bone morphogenetic proteins - considered osteogenic differentiation promoters $^{35}$ - are constituents of the demineralized bone matrix, the Alizarin Red staining and Osterix/Sp7 marking were negative in relation to the cells cultured with the Bonefill granules. In addition, no hydroxyapatite-like crystal deposits were detected by SEM. Thus, the tested demineralized bone matrix was not able to induce osteogenic differentiation of the MSCs.

The biomaterial hydroxyapatite may be of natural origins (derived from corals or bovine bone) or synthetic (hydroxyapatite, unsintered apatite or calcium-deficient apatite) ${ }^{37}$. Synthetic hydroxyapatite may be prepared as a dense non-porous or porous form, in either blocks or granules ${ }^{15}$. In the present study, a granular synthetic hydroxyapatite produced by the precipitation method was utilized. The use of hydroxyapatite for tissue engineering has been described for many years, especially due to its osteoconductive property ${ }^{38}$. In addition, hydroxyapatite may be used in combination with stem cells, since it supports osteogenic induction $^{5}$. In the present study, the in vitro MSC growth was slower in the presence of hydroxyapatite granules in comparison with the other tested biomaterials. This was evidenced by the lower cellular confluence at all evaluation moments. The phenotype evaluation under phase microscopy showed cells with fibroblastoid morphology, confirming that the presence of hydroxyapatite did not affect cell growth. The Alizarin Red staining was positive, indicating the commencement of extracellular calcified matrix deposition. Furthermore, the Sp7/Osterix protein expression, detected exclusively in the presence of hydroxyapatite granules, 
showed osteogenic differentiation, thus confirming the ability of hydroxyapatite to induce osteogenesis ${ }^{5}$.

Cellular adhesion to the hydroxyapatite granules was confirmed by SEM, although only a few cells had been observed. This finding stands in contrast to a prior study in which $95 \%$ of the cells seeded in hydroxyapatite matrix had adhered to its surface when observed only one day after seeding ${ }^{36}$, and another one in which transparent hydroxyapatite ceramics allowed cellular adhesion, proliferation and osteogenic differentiation of rat $\mathrm{MSCs}^{39}$. Small pores up to $5 \mu \mathrm{m}$ in diameter were observed, by SEM, on the surface of the hydroxyapatite granules. The distribution, regularity and size of these pores are critical factors in cell adhesion and proliferation ${ }^{19}$. The pore size that optimizes the adhesion, differentiation and growth of osteoblasts in the presence of hydroxyapatite granules is about $300-400 \mu \mathrm{m}$, so that in ceramics with pores smaller or larger than this mean, the amount of newly formed bone tissue is diminished. Thus, the low porosity of this hydroxyapatite may have negatively influenced the cellular adhesion and proliferation on its surface.

Although all of the tested biomaterials allow MSC adhesion and proliferation on their surfaces, these characteristics are more intense in the presence of the demineralized bone matrix. Furthermore, the cells differentiate into osteogenic lineage when cultured with hydroxyapatite granules, and commence bone matrix deposition on the surface of castor oil-based polyurethane granules.

\section{Conclusions}

All tested biomaterials were able to support mesenchymal stem cell adhesion and proliferation, and may be used as scaffolds for MSCs in bone tissue engineering. BioOsteo enhances hydroxyapatite-like crystal deposition and hydroxyapatite promotes osteogenic differentiation in early evaluation (seven days).

\section{References}

1. Preston SL, Alison MR, Forbes SJ, Direkze NC, Poulsom R, Wright NA. The new stem cell biology: something for everyone. Mol Pathol. 2003;56:86-96.

2. Oreffo ROC, Cooper C, Mason C, Clements M. Mesenchymal stem cells: lineage, plasticity, and skeletal therapeutic potential. Stem Cell Rev. 2005;1:169-78.

3. Alison MR, Islam S. Attributes of adult stem cells. J Pathol. 2009;217(2):144-60.

4. Minguell JJ, Erices A, Conget P. Mesenchymal stem cells. Exp Biol Med. 2001;226(6):507-20.

5. Caplan AI. Mesenchymal stem cells: cell-based reconstructive therapy in orthopedics. Tissue Eng. 2005;11(7/8):1198-211.

6. Abdi R, Fiorina $\mathrm{P}$, Adra $\mathrm{CN}$, Atkinson $\mathrm{M}$, Sayegh $\mathrm{MH}$. Immunomodulation by mesenchymal stem cells. A potential therapeutic strategy for type 1 diabetes. Diabetes. 2008;57:1759-67.

7. Uccelli A, Moretta L, Pistoia V. Mesenchymal stem cells in health and disease. Nature. 2008;8:726-36.

8. Fibbe WE. Mesenchymal stem cells. A potential source for skeletal repair. Ann Rheum Dis. 2002;61(Suppl 2):ii29-31.

9. Kassem M. Mesenchymal stem cells: biological characteristics and potential clinical applications. Cloning Stem Cells. 2004;6(4):36974.

10. Friedenstein AJ, Petrakova KV, Kurolesova AL. Heterotopic of bone marrow. Analysis of precursor cells for osteogenic and hematopoietic tissues. Transplantation. 1968;6:230-47.

11. Alhadlaq A, Mao JJ. Mesenchymal stem cells: isolation and therapeutics. Stem Cells Dev. 2004;13:436-48.

12. Koc ON, Lazarus HM. Mesenchymal stem cells: heading into the clinic. Bone Marrow Transplant. 2001;27:235-9.

13. Logeart-Avramoglou D, Anagnostou F, Bizios R. Engineering bone: challenges and obstacles. J Cell Mol Med. 2005;9:72-84.

14. Cook SD, Baffes GC, Wolfe MW, Sampath TK, Rueger DC, Whitecloud TS. The effect of recombinant human osteogenic protein-1 on healing of large segmental bone defects. J Bone Joint Surg Am. 1994;76:827-38.

15. Bruder SR, Jaiswal N, Ricalton NS, Mosca JD, Kraus KH, Kadiyala S. Mesenchymal stem cells in osteobiology and applied bone regeneration. Clin Orthop Relat Res. 1998;(355 Suppl):S247-56.

16. Itho $T$, Mochizuki M, Nishimura R, Matsunaga S, Kadosawa T, Kokubo S, Yokota S, Sasaki N. Repair of ulnar segmental defect by recombinant human bone morphogenetic protein-2 in dogs. J Vet Med Sci. 1998;60:451-8.

17. Pereira-Júnior OCM, Rahal SC, Iamaguti P, Felisbino SL, Pavan PT, Vulcano LC. Comparison between polyurethanes containing castor oil (soft segment) and cancellous bone autograft in the treatment of segmental bone defect induced in rabbits. J Biomat Appl. 2007;21:283-97.

18. Goldberg V, Stevenson S. Natural history of autografts and allografts. Clin Orthop. 1987;225:7-16.

19. Olivier V, Faucheux N, Hardouin P. Biomaterial challenges and approaches to stem cell use in bone reconstructive surgery. Drug Discov Today. 2004;9(18):803-11.

20. Giannoudis PV, Dinopoulos H, Tsiridis E. Bone substitutes: an update. Injury. 2005;36:S20-7.

21. Perry CR. Bone repair techniques, bone graft, and bone graft substitutes. Clin Orthop Relat Res. 1999;360:71-86.

22. Khan SN, Tomin E, Lane JM. Clinical applications of bone graft substitutes. Orthop Clin North Am. 2000;31(3):389-98.

23. Ohgushi H, Caplan AI. Stem cell technology and bioceramics: from cell to gene engineering. J Biomed Mater Res. 1999;48:913-27.

24. Warren SM, Nacamuli RK, Song HM, Longaker MT. Tissueengineered bone using mesenchymal stem cells and a biodegradable scaffold. J Craniofac Surg. 2004;15(1):34-7.

25. Vats A, Tolley NS, Polak JM, Buttery LDK. Stem cells: sources and applications. Clin Otolaryngol. 2002;27:227-32.

26. Burg KJL, Porter S, Kellam JF. Biomaterial developments for bone tissue engineering. Biomaterials.2000;21:2347-59.

27. Silva TSN, Primo BT, Silva Júnior AN, Machado DC, Viezzer C, Santos LA. Use of calcium phosphate cement scaffolds for bone tissue engineering: in vitro study. Acta Cir Bras. 2011;26:1-11.

28. Short B, Brouard N, Occhiodoro-Scott T, Ramakrishnan A, Simmons PJ. Mesenchymal stem cells. Arch Med Res. 2003;34:565-71.

29. Kadiyala S, Jaiswal N, Bruder SP. Culture-expanded, bone marrow- 
derived mesenchymal stem cells can regenerate a critical-sized segmental bone defect. Tissue Eng. 1997;3(2):173-85.

30. Bioosteo. Bioosteo. (2010). Available from: <http://www. biomecanica.com.br>. [cited $2010 \mathrm{Jul} 21$ ].

31. Ignácio H. Avaliação da poliuretana da mamona nas formas compacta e porosa no preenchimento da falha óssea. Estudo experimental em cães [thesis]. School of Medicine, Sao Paulo University, Brazil; 1999.

32. Beloti MM, Hiraki KR, Barros VM, Rosa AL. Effect of the chemical composition of Ricinus communis polyurethane on rat bone marrow cell attachment, proliferation, and differentiation. J Biomed Mater Res. 2003;64(1):171-6.

33. Lu JX, Flautre B, Anselme K, Hardouin P, Gallur A, Descamps $\mathrm{M}$, Thierry B. Role of interconnections in porous bioceramics on bone recolonization in vitro and in vivo. J Mater Sci Mater Med. 1999;10(2):111-20.

34. Gebhart M, Lane J. A radiographycal and biomechanical study of demineralized bone matrix implanted into a bone defect of rat femurs with and without bone marrow. Acta Orthop Belg. 1991;57(2):130 43.

35. De Long WG, Einhorn TA, Koval K, Mckee M, Smith W, Sanders $\mathrm{R}$, Watson T. Current concepts review: bone grafts and bone graft substitutes in orthopedic trauma surgery. J Bone Joint Surg Am. 2007;89:649-58.

36. Kasten P, Luginbuhl R, Van Griensven M, Barkhausen T, Krettek C, Bohner M, Bosch U. Comparison of human bone marrow stromal cells seeded on calcium-deficient hydroxyapatite, b-tricalcium phosphate and demineralized bone matrix. Biomaterials. 2003;24:2593-603.

37. Legeros RG. Properties of osteoconductive biomaterials: calcium phosphates. Clin Orthop Relat Res. 2002;395:81-98.

38. Niemeyer P, Krause U, Fellenberg J, Kasten P, Seckinger A, Ho $\mathrm{AD}$, Simank H. Evaluation of mineralized collagen and tricalcium phosphate as scaffolds for tissue engineering of bone using human mesenchymal stem cells. Cells Tissues Organs. 2004;177:68-78.

39. Kotobuki N, Ioku K, Kawagoe D, Fujimori H, Goto S, Ohgushi $\mathrm{H}$. Observation of osteogenic differentiation cascade of living mesenchymal stem cells on transparent hydroxyapatite ceramics. Biomaterials. 2005;26(7):779-85.

\section{Correspondence:}

Sheila Canevese Rahal

Departamento de Cirurgia Veterinária e Anestesiologia

Faculdade de Medicina Veterinária e Ciência Animal-UNESP

Distrito de Rubião Jr., s/n

18618-970 Botucatu - SP Brasil

Tel.: (55 14)3880-2041

sheilacr@fmvz.unesp.br

odujunior@yahoo.com.br

Received: January 16, 2013

Review: March 19, 2013

Accepted: April 18, 2013

Conflict of interest: none

Financial sources: National Council of Technological and Scientific Development (CNPQ), Coordination of Improvement for Higher Academic Staff (CAPES) and PROCAD

${ }^{1}$ Research performed at Department of Veterinary Surgery and Anesthesiology, School of Veterinary Medicine and Animal Science, Sao Paulo State University (UNESP), Botucatu-SP, Brazil. Part of PhD degree thesis, Postgraduate Program in Veterinary Medicine. Tutor: Sheila Canevese Rahal. 